Elsevier Editorial System(tm) for
International Journal of Hydrogen Energy
Manuscript Draft

Manuscript Number: HE-D-13-01541R1

Title: Hydrogen uptake of high surface area-activated carbons doped with nitrogen

Article Type: Full Length Article

Keywords: Hydrogen storage, activated carbon, nitrogen doping

Corresponding Author: Dr. Vanessa Fierro,

Corresponding Author's Institution:

First Author: Weigang Zhao

Order of Authors: Weigang Zhao; Vanessa Fierro; Natalia Fernandez-Huerta; Maria T Izquierdo; Alain Celzard

Abstract: Three activated carbons (ACs) having apparent surface areas higher than $2500 \mathrm{~m} 2 / \mathrm{g}$ were doped with nitrogen by treatment with urea at $623 \mathrm{~K}$ under air flow. Nitrogen contents as high as 15.1 wt. $\%$ were obtained, but resulting in decreased surface areas and pore volumes. Hydrogen storage capacities of ACs before and after nitrogen doping were measured at $77 \mathrm{~K}$ and up to $8 \mathrm{MPa}$. After doping, the hydrogen uptake was lower due to the corresponding decrease of surface area. Statistical, ANOVA, analysis of the relevancy of surface area and nitrogen content on hydrogen storage at $77 \mathrm{~K}$ was carried out, taking into account our data and those data available in the open literature. We concluded that surface area controls hydrogen adsorption and nitrogen content is not a relevant parameter. 


\title{
Hydrogen uptake of high surface area-activated carbons doped with nitrogen
}

\author{
W. Zhao ${ }^{1,2,3}$, V. Fierro ${ }^{* 1}$, N. Fernández-Huerta ${ }^{4}$, \\ M.T. Izquierdo ${ }^{4}$, A. Celzard ${ }^{* * 1,2}$
}

${ }^{1}$ Institut Jean Lamour, UMR CNRS 7198. ENSTIB, 27 rue Philippe Séguin, CS 60036, 88026 Epinal cedex, France

${ }^{2}$ Université de Lorraine. ENSTIB, 27 rue Philippe Séguin, CS 60036, 88026 Epinal cedex, France

${ }^{3}$ College of Material Engineering, Fujian Agriculture \& Forestry University. Fuzhou, Fujian 350002, China

${ }^{4}$ Instituto de Carboquímica (ICB-CSIC), Miguel Luesma Castán, 4. 50018 Zaragoza, Spain

\footnotetext{
* Corresponding author

Fax: +33 3292961 38; e-mail: Vanessa.Fierro@lcsm.uhp-nancy.fr

** Member of the Institut Universitaire de France
} 


\begin{abstract}
Three activated carbons (ACs) having apparent surface areas higher than $2500 \mathrm{~m}^{2} / \mathrm{g}$ were doped with nitrogen by treatment with urea at $623 \mathrm{~K}$ under air flow. Nitrogen contents as high as $15.1 \mathrm{wt}$.\% were obtained, but resulting in decreased surface areas and pore volumes. Hydrogen storage capacities of ACs before and after nitrogen doping were measured at $77 \mathrm{~K}$ and up to $8 \mathrm{MPa}$. After doping, the hydrogen uptake was lower due to the corresponding decrease of surface area. Statistical, ANOVA, analysis of the relevancy of surface area and nitrogen content on hydrogen storage at $77 \mathrm{~K}$ was carried out, taking into account our data and those data available in the open literature. We concluded that surface area controls hydrogen adsorption and nitrogen content is not a relevant parameter.
\end{abstract}




\section{Introduction}

The US Department of Energy (DOE) set three goals for hydrogen storage systems to be used for automotive applications, which are reversibility, gravimetric density around 6 wt.\% [1], and heat of adsorption $\left(\Delta \mathrm{H}_{\mathrm{ads}}\right)$ within the $20-30 \mathrm{~kJ} / \mathrm{mole}$ range [2-3]. High surface area activated carbons (ACs) with optimal pore sizes around $0.5-0.7 \mathrm{~nm}$ have been suggested [4-6] as potential candidates to reach high hydrogen storage capacities at $77 \mathrm{~K}$. If high surface area is indeed necessary, it is not the only requirement and we have shown that an appropriate pore size distribution is also needed. Thus, $\mathrm{H}_{2}$ uptakes higher than 3 wt. $\%$ at $77 \mathrm{~K}$ are due to pores having diameters wider than $0.7 \mathrm{~nm}$ [7-8] in ACs prepared from $\mathrm{KOH}$ activation. Even if surface area and pore size distribution were optimised, we have experimentally shown that a maximum of hydrogen adsorption on ACs exists [9], and this maximum is very close to the 6.6 wt. \% calculated by Schlapbach and Züttel [10].

The typical energy contribution from dispersive forces to hydrogen adsorption in porous solids such as ACs is roughly $6 \mathrm{~kJ} / \mathrm{mole}$, and remains well below the lower limit for the ideal $\Delta \mathrm{H}_{\mathrm{ads}}$ range $(20-30 \mathrm{~kJ} / \mathrm{mole})$. A possible strategy for increasing the strength of the gas-solid interaction, and hence the hydrogen storage capacity of ACs, is the introduction of metal nanoparticles or heteroatoms in the carbon matrix [11]. Thus, doping ACs with Pd nanoparticles was tested as a method for improving hydrogen storage by spillover [12-16]. However, as hydrogen storage on high surface area-ACs at $77 \mathrm{~K}$ primarily depends on microporosity, Pd doping may decrease the micropore volume available for adsorption and hence the hydrogen storage capacities 
Introduction of heteroelements significantly alters the electronic structure of the carbon matrix, thus affects the interactions between solid carbon and adsorbed hydrogen and might increase the amount of hydrogen stored. Promising results were obtained by introducing boron [18], silicon [19], sulphur [20] or nitrogen [21] into carbon. Nitrogen doping has been studied more extensively than the other heteroatoms, but contradictory results were reported in the literature. Zhou et al. [22] studied, through density functional theory (DFT) calculations, the effect of N-doping on hydrogen adsorption on single-walled carbon nanotubes. They found that $\mathrm{N}$ doping decreased the hydrogen molecular adsorption energies. Kang et al. [23] found that hydrogen adsorption at $77 \mathrm{~K}$ was more strongly related to specific surface area than to nitrogen content. Xia et al. [24] found that N-doping can be beneficial at low hydrogen uptake but is detrimental at high hydrogen uptake. Wang et al. [25-26] prepared nitrogen-doped ACs and found that hydrogen storage in such samples was much higher than that of non-doped materials of similar surface area. Finally, other studies concluded that nitrogen doping has no impact on hydrogen storage [27-29].

Therefore, the effect of nitrogen doping on hydrogen storage is still debated and, most of times, it is difficult to separate the combined effects of porosity and chemical composition. In the present manuscript, we doped three high surface area ACs, resulting in materials with nitrogen contents as high as $15.1 \mathrm{wt} \%$. Hydrogen storage capacity of raw and $\mathrm{N}$-doped ACs was measured at $77 \mathrm{~K}$, and our results were compared to those reported in the open literature. 


\section{Experimental}

\subsection{Materials synthesis}

The ACs' precursor was Chinese anthracite from Taisi mine, with an average particle size within the range $100 \sim 200 \mu \mathrm{m}$. ACs were prepared by chemical activation with $\mathrm{KOH}$, as described elsewhere $[9,30]$. Nitrogen doping was then carried out by physical mixing of urea and $\mathrm{AC}$, using urea to $\mathrm{AC}$ weight ratios of either 1 or 2, followed by thermal treatment in a horizontal furnace under air flowing at 50 $\mathrm{cm}^{3} / \mathrm{min}$. Temperature was increased at $5 \mathrm{~K} / \mathrm{min}$ up to $623 \mathrm{~K}$, the final temperature was maintained for $3 \mathrm{~h}$, then the furnace was allowed to cool down to room temperature under air flow. The N-doped ACs were finally washed with hot water until neutral $\mathrm{pH}$ in a Soxhlet extractor, and dried.

\subsection{Physicochemical characterization}

\subsubsection{Nitrogen content determination}

Nitrogen content was determined by elemental analysis (EA) and X-ray photoelectron spectroscopy (XPS). EA was carried out in a ThermoFlash 1112 apparatus to determine carbon, hydrogen, nitrogen and sulphur contents. Oxygen content was obtained by difference. XPS spectra were recorded with an ESCAPlus OMICROM system equipped with a hemispherical electron energy analyzer. The spectrometer was operated at $10 \mathrm{kV}$ and $15 \mathrm{~mA}$ under vacuum $\left(<7 \times 10^{-7} \mathrm{~Pa}\right)$, using a non-monochromatised $\mathrm{Mg} \mathrm{K \alpha} \mathrm{X}$-Ray Source (hv = $1253.6 \mathrm{eV})$. Analyzer pass energies of 50 and $20 \mathrm{eV}$ were used for full and detailed scans, respectively. The $\mathrm{C} 1 \mathrm{~s}$ 
peak at $284.5 \mathrm{eV}$ was used for binding energy correction.

\subsubsection{Nitrogen physisorption}

Nitrogen adsorption-desorption isotherms were obtained at $77 \mathrm{~K}$ using a Micromeritics ASAP 2020 automatic apparatus. The samples were degassed for $48 \mathrm{~h}$ under vacuum at $523 \mathrm{~K}$ prior to any adsorption experiment. Nitrogen adsorption data were obtained and treated as described elsewhere [9,30] for obtaining: (i) apparent surface area, $\mathrm{S}_{\mathrm{BET}}$, by the BET calculation method [31]; (ii) micropore volume, $\mathrm{V}_{\mathrm{DR}}$, according to the Dubinin-Radushkevich (DR) method [32 and refs. therein]; (iii) total pore volume, $\mathrm{V}_{0.99}$, defined as the volume of liquid nitrogen corresponding to the amount adsorbed at a relative pressure $\mathrm{P} / \mathrm{P}_{0}=0.99$ [33]. The mesopore volume, $\mathrm{V}_{\mathrm{me}}$, was calculated as the difference $\mathrm{V}_{0.99}-\mathrm{V}_{\mathrm{DR}}$. The average micropore diameter, $\mathrm{L}_{0}$, and adsorption energy, $\mathrm{E}_{\mathrm{a}}$, were also calculated [34], as well as the pore size distributions (PSD) by application of the Density Functional Theory (DFT) [35].

\subsubsection{Hydrogen storage}

Adsorbed hydrogen uptake at $77 \mathrm{~K}$ was measured with a gravimetric analyzer (VTI Corporation). Hydrogen isotherms were obtained by setting pressure steps within the range $0-8 \mathrm{MPa}$ at 77 and $298 \mathrm{~K}$. More details are given elsewhere $[9,30]$. The counterpart excess hydrogen isotherms were measured in a volumetric device (HPVA-II, Micromeritics) in the same conditions. 


\section{Results and discussion}

\subsection{Materials composition}

\subsubsection{Elemental analysis}

All ACs, non-doped and N-doped, were labelled ACxx'y. In such nomenclature, $\mathrm{x}$ and $\mathrm{x}$ ' correspond to the first two digits of the value of $\mathrm{S}_{\mathrm{BET}}$ for the non-doped $\mathrm{AC}$ ( $\mathrm{N}$-doped AC precursor), whereas y is the weight ratio of urea to AC: 0 for non-doped ACs, and either 1 or 2 for $\mathrm{N}$-doped ACs. For example, AC250 is a raw AC having a $\mathrm{S}_{\mathrm{BET}}$ of $2500 \mathrm{~m}^{2} / \mathrm{g}$, whereas AC251 is the N-doped counterpart prepared from AC250 using an urea/AC weight ratio (W) of 1.

Table 1 shows the results of elemental analysis of all studied ACs. Nitrogen content of raw materials was very low, typically ranging from 0.2 to 0.3 wt. $\%$, whereas that of $\mathrm{N}$-doped ACs was between 7.8 and 15.1 wt.\%. Materials prepared from ACs having $\mathrm{S}_{\mathrm{BET}}$ of 2527,2955 and $3434 \mathrm{~m}^{2} / \mathrm{g}$ with $\mathrm{W}=1$ had nitrogen contents of 7.8, 9.9 and 8.8 wt.\%, respectively. Using $\mathrm{W}=2$ in the AC30y series, the $\mathrm{N}$ content increased from 9.9 to $15.1 \%$ and $\mathrm{C}$ content decreased from 85.3 to $80.2 \%$, whereas $\mathrm{H}$ and $\mathrm{O}$ contents remained roughly constant. These results seem to indicate that the amount of nitrogen in the final product not only depends on the oxygen content of the precursor, as concluded by Pietrzak et al. [36], but also on the value of W. As a result of $\mathrm{N}$-doping treatment in the $\mathrm{AC} 30 \mathrm{y}$ series, $\mathrm{C} / \mathrm{N}$ ratio decreased dramatically and $\mathrm{C} / \mathrm{O}$ ratio moderately increased (from 460.5 to 5.3 and from 12.6 to 20.2 , respectively), essentially due to the decrease of C content. 


\subsubsection{XPS studies}

Figure 1 presents full XPS spectra of $\mathrm{N}$-doped samples. The region corresponding to N1s was carefully studied in order to follow some changes of bonding nitrogen to the carbon structure, as shown in Figure 2, in which the N1s bands were fitted for deconvolution with CASA software. The resultant contributions to N1s peaks are shown in Table 2.

N1s spectra of N-doped ACs were quite similar, all exhibiting an asymmetric, broad, band, whose deconvolution led to 3 contributions (Table 2) associated to different $\mathrm{N}$ functionalities according to the literature [37-48]. The first one at $398.1-$ $398.2 \mathrm{eV}$ can be assigned to pyridinic $\mathrm{N}(\mathrm{N}-6)$, and the second one at $399.4-399.6$ $\mathrm{eV}$ can be assigned to neutral amine (from model compounds reviewed in [48]). The last band ranged from 401.4 to $402.4 \mathrm{eV}$ and, because of its width, could not be unambiguously assigned to only one type of $\mathrm{N}$ functionality. However, $\mathrm{N}-\mathrm{Q}$ type with a low contribution of protonated amines seems to be the most reliable assignation. Therefore, the major contribution to N1s band, ranging from 54 to $73 \%$, was that corresponding to amines. The nitrogen content of ACs before $\mathrm{N}$-doping was so low that accurate $\mathrm{N}$-contribution determination was impossible.

Table 2 also shows the contributions to $\mathrm{C} 1 \mathrm{~s}$ peaks. C1s bands (details not shown) were fitted by two and three peaks for raw and N-doped ACs, respectively. The first peak at $284.8 \mathrm{eV}$ is associated to hydrocarbons (aliphatic and aromatics). The second one is related to both $\mathrm{C}-\mathrm{O}$ single bond (ether, phenol) and to $\mathrm{C}$ associated with N. Such peak appeared at $285.5 \mathrm{eV}$ for raw ACs, being primarily due to aliphatic 
alphacarbons, and at $286.5 \mathrm{eV}$ in $\mathrm{N}$-doped ACs, being due to alcohols, phenols, C-N, carbons in keto-enolic equilibria and $\mathrm{C}-\mathrm{NO}_{2}$. The third peak, at $288.4 \mathrm{eV}$, is related to $\mathrm{C}=\mathrm{O}$ in carbonyl and quinine, and to $\mathrm{C}$ associated with $\mathrm{N}$. For $\mathrm{AC} 302$, such peak appeared at 287.4 instead of at $288.4 \mathrm{eV}$, due to the existence of keto-groups. The area of the first peak increased with the surface area, having a contribution of $32,46.6$ and $51.4 \%$ for $\mathrm{AC} 250, \mathrm{AC} 300$ and $\mathrm{AC} 340$, respectively. Therefore, further activation produced more aliphatic and aromatic hydrocarbons and less $\mathrm{C}-\mathrm{O}$ carbons. After $\mathrm{N}-$ doping, less aliphatic and aromatic hydrocarbons were observed, but the areas of the second and third peaks increased, due to the increased contribution of $\mathrm{C}-\mathrm{N}$ groups.

The chemical compositions determined by EA on one hand, and by XPS on the other hand, are somewhat different. Comparison of Tables 1 and 2 indeed shows that the nitrogen contents are systematically lower at the surface of the materials than in the bulk. These findings are still unclear given that, in contrast, $\mathrm{C} / \mathrm{N}$ and $\mathrm{C} / \mathrm{O}$ ratios measured by both techniques are rather similar in non-doped materials.

\subsection{Porous texture}

Table 3 shows textural parameters determined by $\mathrm{N}_{2}$ adsorption at $77 \mathrm{~K}$ for the 7 ACs considered in this study. All the ACs had apparent surface areas higher than 2000 $\mathrm{m}^{2} / \mathrm{g}$, i.e. between 2082 and $3434 \mathrm{~m}^{2} / \mathrm{g}$. They were mainly microporous since their micropore fraction, $\mathrm{V}_{\mathrm{DR}} / \mathrm{V}_{0.99}$, ranged from 0.63 to 0.82 . After nitrogen doping, a decrease of surface area and pore volume, both in the micro- and in the mesopore range, was observed. Weight ratios urea/AC of 1 and 2 decreased by $15-20 \%$ and by 
$30 \%$ the original surface area of the ACs, respectively. This finding is in agreement with the results of Pietrzag et al. [36].

Figure 3 a) shows the $\mathrm{N}_{2}$ adsorption-desorption isotherms at $77 \mathrm{~K}$ of the AC30y series before $(\mathrm{AC} 300)$ and after $\mathrm{N}$-doping with $\mathrm{W}=1(\mathrm{AC} 301)$ and $\mathrm{W}=2(\mathrm{AC} 302)$. Nitrogen isotherms were type I according to IUPAC classification, characterizing microporous adsorbents. N-doping treatment with urea did not affect the isotherm shape but all pore volumes, irrespective to the pore width. Figure $3 \mathrm{~b}$ ) shows the PSD of the same AC series, confirming the conclusion derived from nitrogen isotherms. A clear decrease of all kinds of pore volumes was indeed observed when W was increased. Different from $\mathrm{KOH}$ activation, which has been thoroughly studied and activation mechanisms well explained $[8,49,50]$, urea treatment effect on surface area is still under discussion. Pietrzag et al. [36] observed that urea treatment produced a surface increase on coals carbonized at $773 \mathrm{~K}$ but a surface decrease on coals carbonized at $973 \mathrm{~K}$. They proposed that urea acts removing amorphous carbon blocking pores as well as creating new micropores and this effect was particularly important at low temperature. When urea treatment was applied to ACs prepared by $\mathrm{KOH}$ activation, it always produced surface area reduction [36]. Reduction of surface area when activated carbons were submitted to urea treatment was also found by other authors [51,52]. Arenillas et al. [51] suggested that the incorporation of nitrogen species to the edges of grapheme layers may create steric hindrances and partially block the access of nitrogen to pores.

Figure 4 shows the effect of nitrogen content determined by elemental analysis, 
N-EA (\%), on the values of $S_{B E T}$ for the 3 AC series. Changes of $S_{B E T}$ versus N-EA, just like those of $\mathrm{V}_{\mathrm{DR}}$ (not shown), evidenced a nearly linear decrease. The discontinuous line is only a guide for the eye, and it can indeed be easily observed that we might also have drawn up three parallel lines corresponding to the $3 \mathrm{AC}$ series.

\subsection{Hydrogen storage capacity}

Figure 5 a) shows hydrogen adsorption-desorption isotherms of the AC30y series at $77 \mathrm{~K}$ and up to $8 \mathrm{MPa}$. All the isotherms were type I, and a plateau was reached at $4 \mathrm{MPa}$. Hydrogen adsorption was completely reversible with high adsorption/desorption kinetics. Hydrogen adsorption was lower after nitrogen doping due to the decrease of $\mathrm{S}_{\mathrm{BET}}$, as demonstrated above, so that hydrogen adsorption capacity decreased in the order AC300 > AC301 > AC302. The same behaviour was observed in the other AC series.

Figure $5 \mathrm{~b}$ ) presents the hydrogen adsorption capacities of the AC30y series as a function of $\mathrm{N}$ content. ACs before doping showed outstanding capacities of 5.4, 6.0 and 6.5 wt.\% at $77 \mathrm{~K}$ due to their high $\mathrm{S}_{\mathrm{BET}}, 2527,2955$ and $3434 \mathrm{~m}^{2} / \mathrm{g}$, respectively. $\mathrm{N}$-doped ACs had adsorbed hydrogen uptakes within the range $4.4-5.4$ wt.\%, i.e. always lower than those of their precursors. Therefore, N-doping appears to have a negative effect on the hydrogen storage capacity at $77 \mathrm{~K}$ for the $3 \mathrm{AC}$ series. Indeed, as explained above and as evidenced in Figure 4, the introduction of nitrogen into carbon by urea treatment produced a decrease of $\mathrm{S}_{\mathrm{BET}}$. 
Excess hydrogen uptake, $\mathrm{H}_{2}$ excess, is commonly reported and represents the amount of gas which is adsorbed additionally to the gas that would be present in the pore if there was no adsorption. For this reason, Figure 6 shows hydrogen excess uptake as a function of $\mathrm{S}_{\mathrm{BET}}$ for 36 non-doped Taisi ACs [7-9, 30, 50] and the 7ACs reported in this study. Differences in $\mathrm{H}_{2}$ excess are within the experimental error interval and, from this figure, it might be concluded that $\mathrm{S}_{\mathrm{BET}}$ controls hydrogen storage at $77 \mathrm{~K}$ while nitrogen content has no effect. In order to confirm that, we will compare our results to those obtained in former studies in the next section.

3.4 Effect of nitrogen content, comparison with other literature data

Most of hydrogen storage capacities reported in the open literature were measured at a lower pressure than for our own data, i.e. at $2 \mathrm{MPa}$ instead of $4 \mathrm{MPa}$ [23, 24, 28, 29]. Figure 7 a) and b) shows $\mathrm{H}_{2}$ excess uptake at $2 \mathrm{MPa}$ as a function of $\mathrm{S}_{\mathrm{BET}}$ and nitrogen content for the aforementioned references and our data. In these former studies, nitrogen content was determined by XPS [24, 29] (Figure 7 a) or EA $[23,24,28]$ (Figure 7 b). XPS gives nitrogen content at the surface of the materials, whereas EA gives nitrogen content in the bulk. These two kinds of measurement give results that are sometimes quite different. Therefore, nitrogen contents determined by XPS and by EA were treated separately. $\mathrm{H}_{2}$ excess is clearly dependent on $\mathrm{S}_{\mathrm{BET}}$ but it is difficult to see the effect of nitrogen content, especially in Figure 7a). For this reason, we applied the analysis of variance (ANOVA) not only to results reported in literature but also to our results. ANOVA is a method of partitioning variability into 
identifiable sources of variation and the associated degrees of freedom in an experiment. The ANOVA was done at $95 \%$ confidence level ( $\alpha$ level), based on the sum of the squares $(S S)$, the degree of freedom $(d f)$, the mean square, and $F$ and $P$ values. Usually, the larger the $F$ value, the greater the effect of an experimental variable on the results [53]. Table 4 shows the results of ANOVA for a linear model where $\mathrm{H}_{2}$ excess would be a function of $\mathrm{S}_{\mathrm{BET}}$ and $\mathrm{N}$ content, determined by XPS or EA. The highest $F$ values were obtained for $S_{\mathrm{BET}}$, thus confirming that $\mathrm{S}_{\mathrm{BET}}$ has the most important effect on hydrogen storage. The last column gives $P$ values. If a $P$ value is less than, or equal to, $\alpha$ level ( 0.05 in this case), then the variable has no significant effect. We can observe that only $\mathrm{N}$ content has a $P$ value higher than $0.05: 0.149$ (for $\mathrm{N}$ determined by XPS) and 0.063 (for $\mathrm{N}$ determined by EA). Therefore, we can conclude that nitrogen content has no significant effect on hydrogen storage at $77 \mathrm{~K}$.

Figure 8 shows excess $\mathrm{H}_{2}$ uptake as a function of $\mathrm{S}_{\mathrm{BET}}$ for the data reported in the literature $[23,24,28,29]$ and data obtained this study. $\mathrm{H}_{2}$ excess is linearly dependent on $\mathrm{S}_{\mathrm{BET}}$ up to $2630 \mathrm{~m}^{2} / \mathrm{g}$, which is the theoretical maximum surface of carbon $[9,10,50]$, and this is in agreement with the ANOVA analysis.

\section{Conclusions}

Urea treatment at $623 \mathrm{~K}$ under air flow allowed synthesising ACs with nitrogen contents as high as $15.1 \mathrm{wt} . \%$. However, apparent surface areas and pore volumes were considerably decreased, and hence hydrogen storage capacities were lower after $\mathrm{N}$-doping. 
Statistical analysis, ANOVA, of the relevancy of $\mathrm{S}_{\mathrm{BET}}$ and nitrogen content on hydrogen storage at $77 \mathrm{~K}$ was carried out, taking into account our data and those data available in the open literature. An ANOVA analysis was done for samples analysed by EA and a second one for samples analysed by XPS. Both ANOVA analyses showed that: (i) $\mathrm{S}_{\mathrm{BET}}$ controls hydrogen adsorption, and (ii) nitrogen content is not a relevant parameter.

\section{Acknowledgements}

The French authors from IJL laboratory gratefully acknowledge the financial support of the CPER 2007-2013 "Structuration du Pôle de Compétitivité Fibres Grand'Est" (Competitiveness Fibre Cluster), through local (Conseil Général des Vosges), regional (Région Lorraine), national (DRRT and FNADT) and European (FEDER) funds. Finally, we thank ACTHYF (GDR-CNRS 3270), CNRS thematic group, and $\mathrm{HyPaC}$ platform for fruitful discussions. 


\section{References}

[1] http://www1.eere.energy.gov/hydrogenandfuelcells/storage/pdfs/targets_onbo ard_hydro_storage_explanation.pdf

[2] Bhatia SK, Myers AL. Optimum conditions for adsorptive storage. Langmuir 2006;22:1688-700.

[3] Zhao Y, Kim YK, Dillon AC, Heben MJ, Zhang SB. Hydrogen storage in novel organometallic buckyballs. Phys Rev Lett 2005;94:155504 1-4.

[4] Georgiev PA, Ross DK, Albers P, Ramírez-Cuesta AJ. The rotational and translational dynamics of molecular hydrogen physisorbed in activated carbon: A direct probe of microporosity and hydrogen storage performance. Carbon $2006 ; 44: 2724-38$.

[5] Celzard A, Fierro V, Marêché JF, Furdin G. Advanced preparative strategies for activated carbons designed for the adsorptive storage of hydrogen. Adsorpt Sci Technol 2007;25:129-42.

[6] Gogotsi Y, Portet C, Osswald S, Simmons JM, Yildirim T, Laudisio G, et al. Importance of pore size in high-pressure hydrogen storage by porous carbons. Int J Hydrogen Energy 2009;34:6314-19.

[7] Zhao W, Fierro V, Zlotea C, Aylon E, Izquierdo MT, Latroche M, et al. Activated carbon with appropriate micropore size distribution for hydrogen adsorption. Int J Hydrogen Energy 2011;36:1-4.

[8] Zhao W, Fierro V, Zlotea C, Aylon E, Izquierdo MT, Latroche M, et al. Optimization of activated carbons for hydrogen storage. Int J Hydrogen Energy 
2011;36:11746-51.

[9] Fierro V, Szczurek A, Zlotea C, Marêché JF, Izquierdo MT, Albiniak A, et al. Experimental evidence of an upper limit for hydrogen storage at $77 \mathrm{~K}$ on activated carbons. Carbon 2010;48:1902-11.

[10] Schlapbach L, Züttel A. Hydrogen-storage materials for mobile applications. Nature 2001;414:353-8.

[11] Reguera E. Materials for Hydrogen Storage in Nanocavities: Design criteria. Int J Hydrogen Energy 2009;34:9163-7.

[12] Lachawiec AJ, Qi GS, Yang RT. Hydrogen storage in nanostructured carbons by spillover: Bridge-building enhancement. Langmuir 2005;21:11418-24.

[13] Anson A, Lafuente E, Urriolabeitia E, Navarro R, Benito AM, Maser WK, et al. Hydrogen capacity of palladium-loaded carbon materials. J Phys Chem B 2006;110:6643-8.

[14] Wang L, Yang FH, Yang RT. Effect of surface oxygen groups in carbons on hydrogen storage by spillover. Ind Eng Chem Res 2009;48:2920-6.

[15] Huang CC, Chen HM, Chen CH. Hydrogen storage on modified activated carbon. Int J Hydrogen Energy 2010;35:2777-80.

[16] Bhat VV, Cristian I, Contescu CI, Gallego NC. Kinetic effect of Pd additions on the hydrogen uptake of chemically-activated ultramicroporous carbon. Carbon 2010;48:2361-4.

[17] Zhao W, Fierro V, Zlotea C, Izquierdo MT, Latroche M, Celzard A. Activated carbons doped with $\mathrm{Pd}$ nanoparticles for hydrogen storage. Int $\mathrm{J}$ Hydrogen 
Energy 2012;37:5072-80.

[18] Sankaran M, Viswanathan B, Srinivasa Murthy S. Boron substituted carbon nanotubes-How appropriate are they for hydrogen storage?. Int J Hydrogen Energy 2008;33:393-403.

[19] Cho JH, Yang SJ, Kunsil L, Park CR. Si-doping effect on the enhanced hydrogen storage of single walled carbon nanotubes and graphene. Int $\mathbf{J}$ Hydrogen Energy 2011;36:12286-95.

[20] Sevilla M, Fuertes AB, Mokaya R. Preparation and hydrogen storage capacity of highly porous activated carbon materials derived from polythiophene. Int J Hydrogen Energy 2011;36:15658-63.

[21] Jiang J, Gao Q, Zheng Z, Xia K, Hu J. Enhanced room temperature hydrogen storage capacity of hollow nitrogen-containing carbon. Int J Hydrogen Energy $2010 ; 35: 210-16$

[22] Zhou Z, Gao X, Yan J, Song D. Doping effects of B and N on hydrogen adsorption in single-walled carbon nanotubes through density functional calculations. Carbon 2006;44:939-47.

[23] Kang KY, Lee BI, Lee JS. Hydrogen adsorption on nitrogen-doped carbon xerogels. Carbon 2009;47:1171-80.

[24] Xia Y, Walker GS, Grant DM, Mokaya R. Hydrogen storage in high surface area carbons: experimental demonstration of the effects of nitrogen doping. J AM CHEM SOC 2009;131:16493-9.

[25] Wang L, Yang RT. Hydrogen storage properties of N-doped microporous carbon. 
J Phys Chem C 2009;113:21883-8.

[26] Wang L, Yang FH, Yang RT. Hydrogen storage properties of B- and N-doped microporous carbon. AIChE J 2009;55:1823-33.

[27] Yang Z, Xia Y, Sun X, Mokaya R. Preparation and hydrogen storage properties of zeolite-templated carbon materials nanocast via chemical vapor deposition: effect of the zeolite template and nitrogen doping. J Phys Chem B 2006;110:18424-31.

[28] Giraudet S, Zhu Z, Yao X, Lu G. Ordered mesoporous carbons enriched with nitrogen: application to hydrogen storage. J Phys Chem C 2010;114:8639-45.

[29] Xia Y, Mokaya R, Grant DM, Walker GS. A simplified synthesis of N-doped zeolite-templated carbons, the control of the level of zeolite-like ordering and its effect on hydrogen storage properties. Carbon 2011;49:844-53.

[30] Fierro V, Zhao W, Izquierdo MT, Aylon E, Celzard A. Adsorption and compression contributions to hydrogen storage in activated anthracites. Int $\mathbf{J}$ Hydrogen Energy 2010;35:9038-45.

[31] Brunauer S, Emmet PH, Teller E. Adsorption of gases in multimolecular layers. J Am Chem Soc 1938;60:309-19.

[32] Dubinin MM. Fundamentals of the theory of adsorption in micropores of carbon adsorbents-Characteristics of their adsorption properties and microporous structures. Carbon 1989;27:457-67.

[33] Gregg SJ, Sing KSW. Adsorption, surface area and porosity. 2nd ed. London: Academic Press; 1982. 
[34] Stoeckli F, Slasli A, Hugi-Cleary D, Guillot A. The characterization of microporosity in carbons with molecular sieve effects. Micropor Mesopor Mat 2002;51:197-202.

[35] Tarazona P. Solid-fluid transition and interfaces with density functional approaches. Surf Sci 1995;331-333:989-94.

[36] Pietrzak R, Wachowska H, Nowicki P. Preparation of nitrogen-enriched activated carbons from brown coal. Energy Fuels 2006;20:1275-80.

[37] Pels JR, Kapteijn F, Moulijn JA, Zhu Q, Thomas KM. Evolution of nitrogen functionalities in carbonaceous materials during pyrolysis. Carbon 1995;33:1641-53.

[38] Yoshida, T. An X-Ray Photoelectron Spectroscopic Study of Several Ligands in Coordination Compounds. Bull. Chem. Soc. Jpn. 1980, 53, 1327-30.

[39] Barber M, Connor JA, Guest MF, Hillier IH, Schwarz M, Stacey MJ. Bonding in some donor-acceptor complexes involving boron trifluoride. Study by means of ESCA and molecular orbital calculations. Chem. Soc., Faraday Trans. II $1973 ; 69: 551-8$.

[40] Schmiers H, Friebel J, Streubel P, Hesse R, Köpsel R. An X-Ray Photoelectron Spectroscopic Study of Several Ligands in Coordination Compounds. Carbon 1999;37:1965-78.

[41] Lahaye J, Nanse G, Bagreev A, Strelko V. Porous structure and surface chemistry of nitrogen containing carbons from polymers. Carbon 1999;37:58590. 
[42] Raymundo-Piñero E, Cazorla-Amoros D, Linares-Solano A, Find J, Wild U, Schlögl R. Structural characterization of N-containing activated carbon fibers prepared from a low softening point petroleum pitch and a melamine resin. Carbon 2002;40:597-608.

[43] Kambara S, Takarada T, Toyoshima H, Kato K. Relation between functional forms of coal nitrogen and NOx emissions from pulverized coal combustion. Fuel 1995;74:1247-53.

[44] Wojtowicz MA, Pels JR, Moulijn JA. The fate of nitrogen functionalities in coal during pyrolysis and combustion. Fuel 1995;74:507-16.

[45] Kelemen SR, Gorbaty ML, Kwiatek PJ. Quantification of Nitrogen Forms in Argonne Premium Coals. Energy Fuels 1994;8:896-906.

[46] Desimoni E, Salvi AM, Langerame F, Watts JF. X-ray photoelectron spectroscopy, X-ray excited Auger electron spectroscopy and time-of-flight secondary ion mass spectroscopy characterization of carbon fibres activated by d.c. corona discharge at ambient pressure and temperature. J Electron Spectrosc Relat Phenom 1997;85:179-91.

[47] Wenzhong S, Zhijie L, Yihong L. Surface Chemical Functional Groups Modification of Porous Carbon. Recent Patents on Chemical Eng 2008;1:27-40.

[48] Cagniant D, Gruber R, Boudou JP, Bilem C, Bimer J, Salbut PD. Structural Characterization of Nitrogen-Enriched Coals. Energy Fuels 1998;12:672-81.

[49] Armandi M, Bonelli B, Geobaldo F, Garrone E Nanoporous carbon materials obtained by sucrose carbonization in the presence of $\mathrm{KOH}$. Micropor Mesopor Mat 2010;132, 414-420. 
[50] Zhao W, Fierro V, Fernández-Huerta N, Izquierdo MT, Celzard A. Impact of synthesis conditions of $\mathrm{KOH}$ activated carbons on their hydrogen storage capacities Int J Hydrogen Energy 2012;37:14278-84.

[51] Arenillas A, Rubiera F, Parra JB, Ania CO, Pis JJ. Surface modification of low cost carbons for their application in the environmental protection. Appl Surf Sci $2005 ; 252,619-624$.

[52] Bashkova S, Bandosz TJ.The effects of urea modification and heat treatment on the process of NO2 removal by wood-based activated carbon. J Coll Interf Sci 2009;333, 97-103

[53] Montgomery DC. Design and Analysis of Experiments. New York: John Wiley \& Sons; 1996. 


\section{Captions of the Figures}

Figure 1. XPS survey for N-doped samples.

Figure 2. Experimental XPS N1s spectra of N-doped samples and corresponding deconvolution of the fit (colour online).

Figure 3. Effect of $\mathrm{W}$ : a) on the $\mathrm{N}_{2}$ adsorption - desorption (full and empty symbols, respectively) isotherms at $77 \mathrm{~K}$, and $\mathrm{b}$ ) on the pore-size distribution of the AC30y series $(\diamond \mathrm{AC} 300, \Delta \mathrm{AC} 301$ and $\bullet \mathrm{AC} 302)$.

Figure 4. Changes of $\mathrm{S}_{\mathrm{BET}}$ with $\mathrm{N}$ content determined by EA ( $\bullet$ AC25y series, -AC30y series and $\triangle \mathrm{AC} 35 \mathrm{y}$ series)

Figure 5. a) Hydrogen adsorption isotherms at $77 \mathrm{~K}$ of the AC30y series; b) Changes of hydrogen adsorption with $\mathrm{N}$-content determined by EA.

Figure 6. $\mathrm{H}_{2}$ excess uptakes at $77 \mathrm{~K}$ and $4 \mathrm{MPa}$ as a function of $\mathrm{S}_{\mathrm{BET}}$ for 36 nondoped ( $\square$ ) and this study ( $\square$ ) ACs, all of them derived from Taisi anthracite.

Figure 7. $\mathrm{H}_{2}$ excess uptakes at $77 \mathrm{~K}$ and $2 \mathrm{MPa}$ as a function of $\mathrm{S}_{\mathrm{BET}}$ and nitrogen content determined by a) XPS and b) EA $(\diamond[23], \bullet[24], \diamond[28], \circ[29]$ our data).

Figure 8. $\mathrm{H}_{2}$ excess uptakes at $77 \mathrm{~K}$ and $2 \mathrm{MPa}$ as a function of $\mathrm{S}_{\mathrm{BET}}$ (same symbols as in Figure 7). 
Hydrogen uptake of high surface area-activated carbons doped with nitrogen W. Zhao et al.

Table 1. Elemental analysis (EA) of all $\mathrm{ACs}$, and corresponding $\mathrm{C} / \mathrm{N}$ and $\mathrm{C} / \mathrm{O}$ weight ratios.

\begin{tabular}{|c|c|c|c|c|c|c|c|}
\hline \multirow{2}{*}{ Sample } & \multicolumn{5}{|c|}{ EA (wt.\%) } & \multirow[b]{2}{*}{$\mathrm{C} / \mathrm{N}$} & \multirow[b]{2}{*}{$\mathrm{C} / \mathrm{O}$} \\
\hline & C & $\mathbf{H}$ & $\mathbf{N}$ & $\mathbf{S}$ & $\mathbf{O}$ & & \\
\hline AC250 & 92.96 & 0.42 & 0.31 & 0.00 & 6.31 & 299.87 & 14.73 \\
\hline AC251 & 84.63 & 2.63 & 7.83 & 0.00 & 4.91 & 10.81 & 17.23 \\
\hline AC300 & 92.10 & 0.36 & 0.20 & 0.00 & 7.34 & 460.50 & 12.55 \\
\hline AC301 & 85.28 & 0.54 & 9.90 & 0.00 & 4.28 & 8.61 & 19.92 \\
\hline AC302 & 80.23 & 0.72 & 15.07 & 0.00 & 3.98 & 5.32 & 20.16 \\
\hline AC340 & 93.95 & 0.32 & 0.24 & 0.00 & 5.49 & 391.46 & 17.11 \\
\hline AC 341 & 86.56 & 0.47 & 8.78 & 0.47 & 3.72 & 9.86 & 23.27 \\
\hline
\end{tabular}

*Determined by difference 
Hydrogen uptake of high surface area-activated carbons doped with nitrogen W. Zhao et al.

Table 2. Contributions to N1s and C1s bands in XPS patterns in terms of binding energy (BE, eV) and area of the peak (\%), and corresponding surface compositions (wt.\%).

\begin{tabular}{|c|c|c|c|c|c|c|c|c|c|c|c|}
\hline \multirow{4}{*}{ Sample } & \multicolumn{6}{|c|}{$\mathrm{BE}(\mathrm{eV})$ and area of the peak $(\%)$} & \multicolumn{3}{|c|}{ (wt.\%) } & \multirow{4}{*}{$\mathrm{C} / \mathrm{N}$} & \multirow{4}{*}{$\mathrm{C} / \mathrm{O}$} \\
\hline & \multicolumn{3}{|c|}{ N1s peak } & \multicolumn{3}{|c|}{ C1s peak } & $\mathrm{C}$ & $\mathrm{N}$ & $\mathrm{O}$ & & \\
\hline & Pyridinic & Neutral & Quaternary-N & Hydrocarbons & C-O (ether, phenol) & $\mathrm{C}=\mathrm{O}$ (carbonyl, quinone) & & & & & \\
\hline & $(\mathrm{N}-6)$ & amines & $(\mathrm{N}-\mathrm{Q})$ & (aliphatic, aromatic) & $\mathrm{C}$ associated with $\mathrm{N}$ & C associated with $\mathrm{N}$ & & & & & \\
\hline AC250 & $398.3(7)$ & 400.7 (43) & $401.9(50)$ & $284.4(32.9)$ & $285.6(67.1)$ & & 91.7 & 0.3 & 8.0 & 305.7 & 11.5 \\
\hline $\mathrm{AC} 251$ & $398.2(17)$ & $399.6(63)$ & $402.4(20)$ & 284.4 (47.8) & $286.4(52.2)$ & & 89.1 & 5.1 & 5.8 & 17.5 & 15.4 \\
\hline AC300 & $398.2(2)$ & $400.8(12)$ & $401.9(84.9)$ & 284.4 (46.6) & $285.4(53.6)$ & & 89.5 & 0.2 & 10.3 & 447.5 & 8.7 \\
\hline AC301 & $398.2(20)$ & $399.6(54)$ & $401.4(26)$ & $284.4(43.1)$ & $286.6(53.2)$ & $288.8(3.7)$ & 84.4 & 5.4 & 10.2 & 15.6 & 7.6 \\
\hline AC302 & $398.1(24)$ & 399.4 (55) & $401.8(20)$ & $284.4(36.1)$ & $286.7(57.7)$ & $287.4(6.2)$ & 83.9 & 7.1 & 9.0 & 11.8 & 9.3 \\
\hline AC340 & n.d. & n.d. & n.d. & $284.4(51.4)$ & $285.7(48.6)$ & & 93.6 & 0.1 & 6.3 & 936.0 & 14.9 \\
\hline AC341 & $398.2(7)$ & $399.4(73)$ & $401.6(20)$ & $284.4(41.1)$ & $286.4(52.7)$ & $288.4(6.1)$ & 87.0 & 3.5 & 9.5 & 24.9 & 9.2 \\
\hline
\end{tabular}


Hydrogen uptake of high surface area-activated carbons doped with nitrogen W. Zhao et al.

Table 3 Textural parameters of all ACs.

\begin{tabular}{cccccccc}
\hline & $\begin{array}{c}\mathrm{S}_{\mathrm{BET}} \\
\left(\mathrm{m}^{2} / \mathrm{g}\right)\end{array}$ & $\begin{array}{c}\mathrm{V}_{0.99} \\
\left(\mathrm{~cm}^{3} / \mathrm{g}\right)\end{array}$ & $\begin{array}{c}\mathrm{V}_{\mathrm{DR}} \\
\left(\mathrm{cm}^{3} / \mathrm{g}\right)\end{array}$ & $\begin{array}{c}\mathrm{Ea} \\
(\mathrm{kJ} / \mathrm{mol})\end{array}$ & $\begin{array}{c}\text { Lo } \\
(\mathrm{nm})\end{array}$ & $\begin{array}{c}\mathrm{V}_{\mathrm{DR}} / \mathrm{V}_{0.99} \\
\text { samples }\end{array}$ & $\begin{array}{c}\mathrm{V}_{\mathrm{me}} \\
\left(\mathrm{cm}^{3} / \mathrm{g}\right)\end{array}$ \\
\hline AC250 & 2527 & 1.10 & 0.90 & 22.1 & 1.0 & 0.82 & 0.19 \\
AC251 & 2082 & 0.89 & 0.72 & 23.0 & 0.9 & 0.81 & 0.17 \\
AC300 & 2955 & 1.39 & 1.01 & 20.3 & 1.2 & 0.73 & 0.38 \\
AC301 & 2541 & 1.12 & 0.82 & 21.4 & 1.1 & 0.74 & 0.29 \\
AC302 & 2160 & 0.96 & 0.70 & 21.8 & 1.0 & 0.73 & 0.26 \\
AC340 & 3434 & 1.61 & 1.02 & 19.3 & 1.4 & 0.63 & 0.59 \\
AC341 & 2737 & 1.29 & 0.84 & 20.5 & 1.2 & 0.65 & 0.45 \\
\hline
\end{tabular}


Hydrogen uptake of high surface area-activated carbons doped with nitrogen W. Zhao et al.

Table 4 ANOVA parameters for [23, 24, 28, 29] and our data

\begin{tabular}{|c|c|c|c|c|}
\hline & $S S$ & $d f$ & $F$ & $P$ \\
\hline \multicolumn{5}{|c|}{ N determined by XPS (Figure 7a) } \\
\hline $\mathrm{S}_{\mathrm{BET}}$ & 117.664 & 1 & 771.670 & 0.000 \\
\hline $\mathrm{N}$ & 0.350 & 1 & 2.294 & 0.149 \\
\hline Error & 2.440 & 16 & & \\
\hline Total & 407.331 & 18 & & \\
\hline \multicolumn{5}{|c|}{ N determined by EA (Figure 7b) } \\
\hline $\mathrm{S}_{\mathrm{BET}}$ & 226.104 & 1 & 2173.152 & 0.000 \\
\hline $\mathrm{N}$ & 0.397 & 1 & 3.819 & 0.063 \\
\hline Error & 2.393 & 23 & & \\
\hline Total & 359.887 & 25 & & \\
\hline
\end{tabular}


Hydrogen uptake of high surface area-activated carbons doped with nitrogen W. Zhao et al.

$\underline{\text { Figure } 1}$

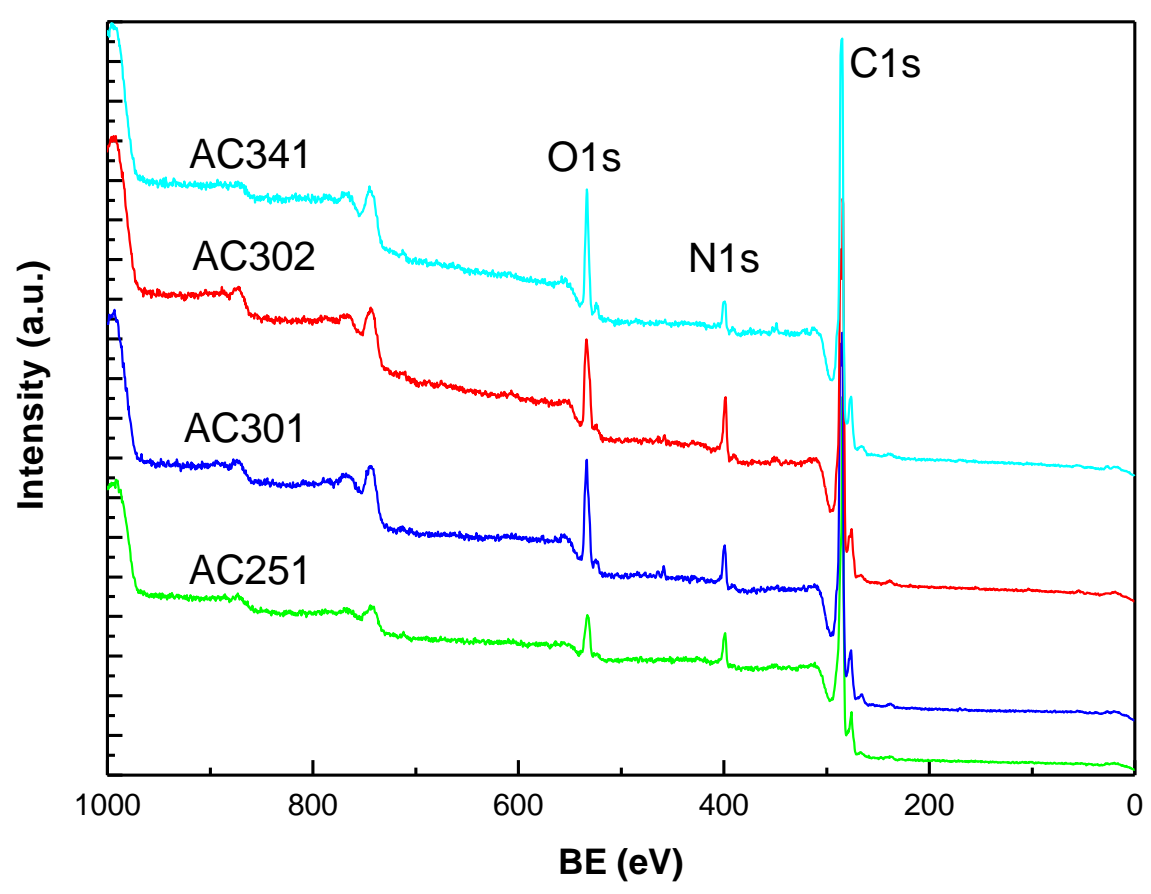


Hydrogen uptake of high surface area-activated carbons doped with nitrogen W. Zhao et al.

\section{Figure 2}
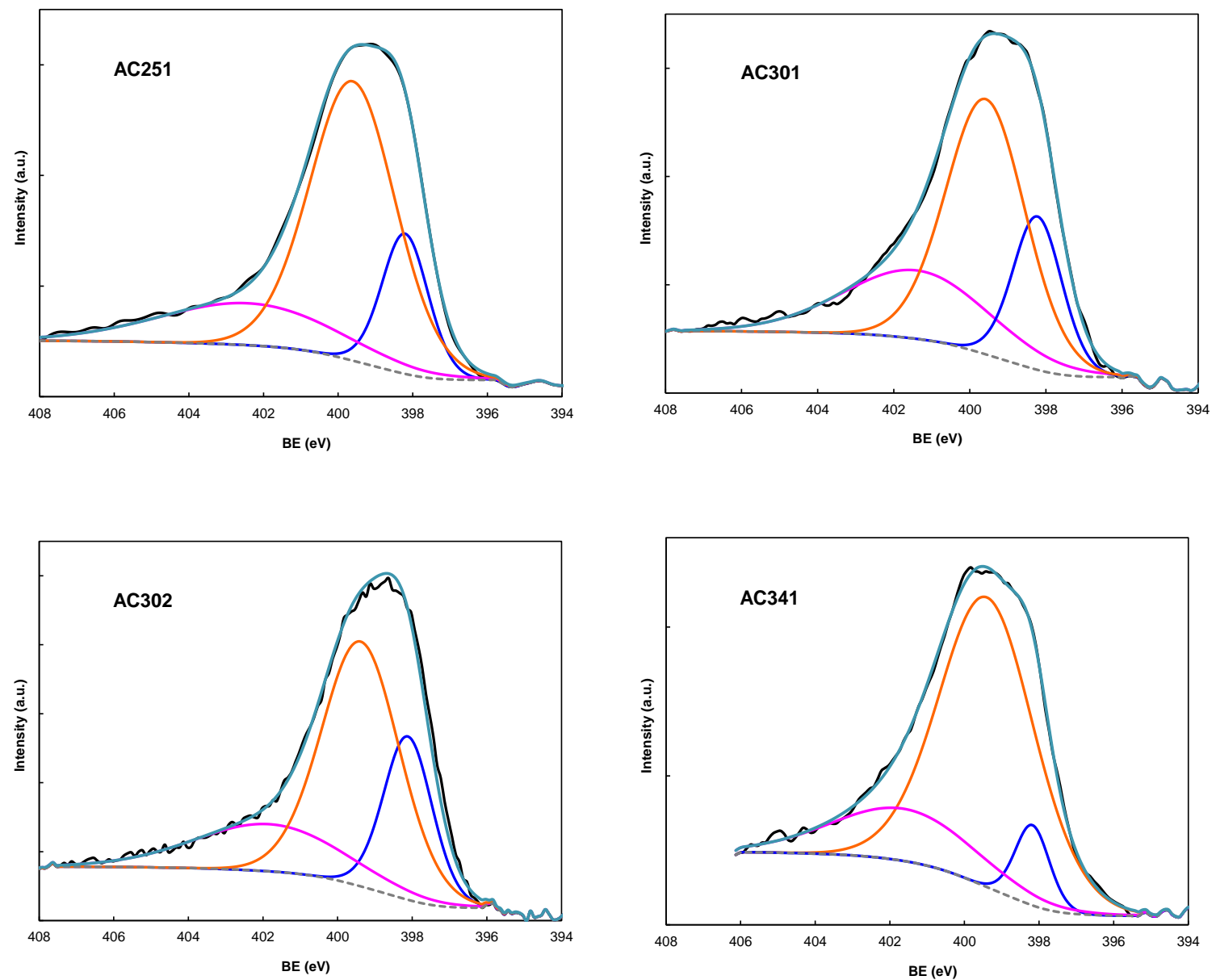
Hydrogen uptake of high surface area-activated carbons doped with nitrogen W. Zhao et al.

Figure 3

a)

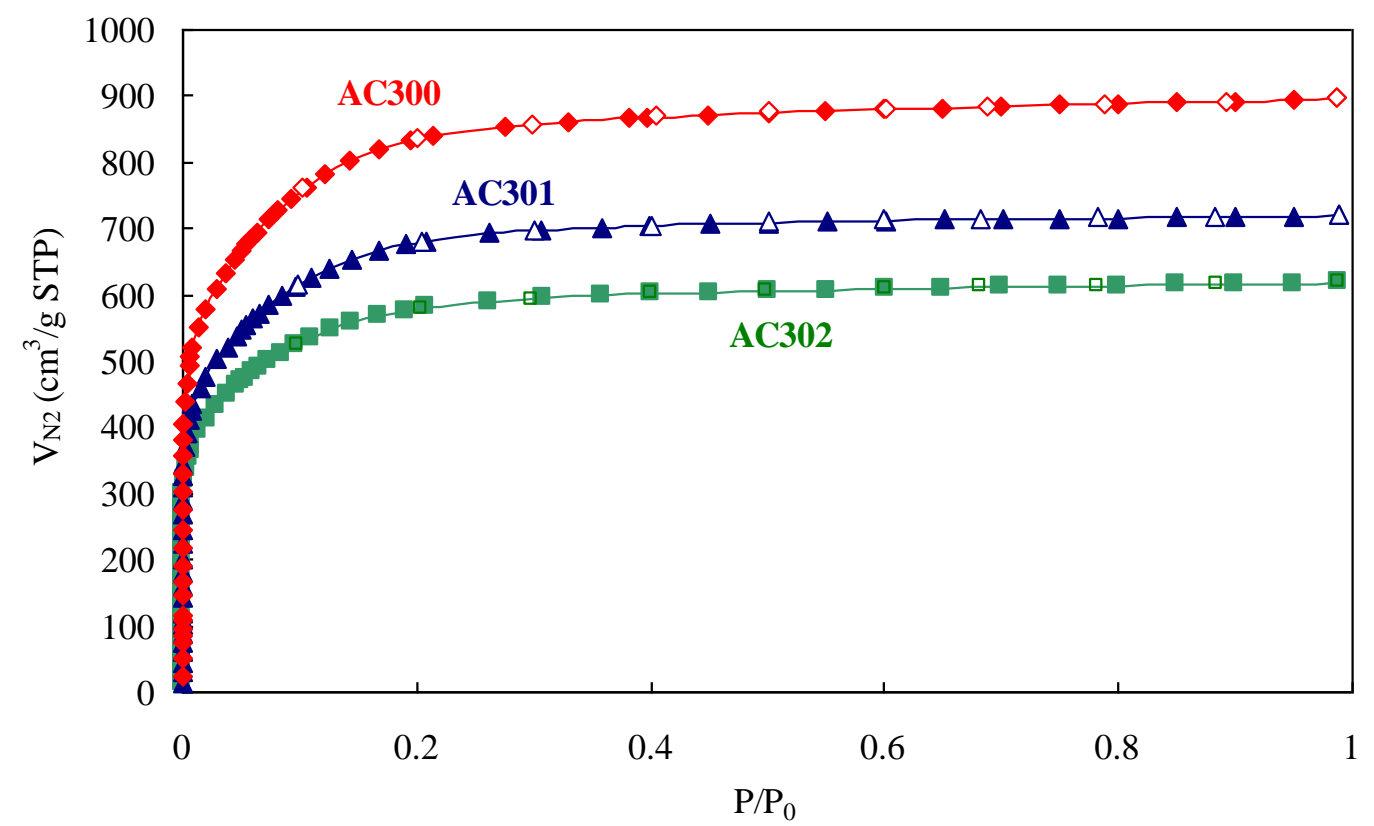

b)

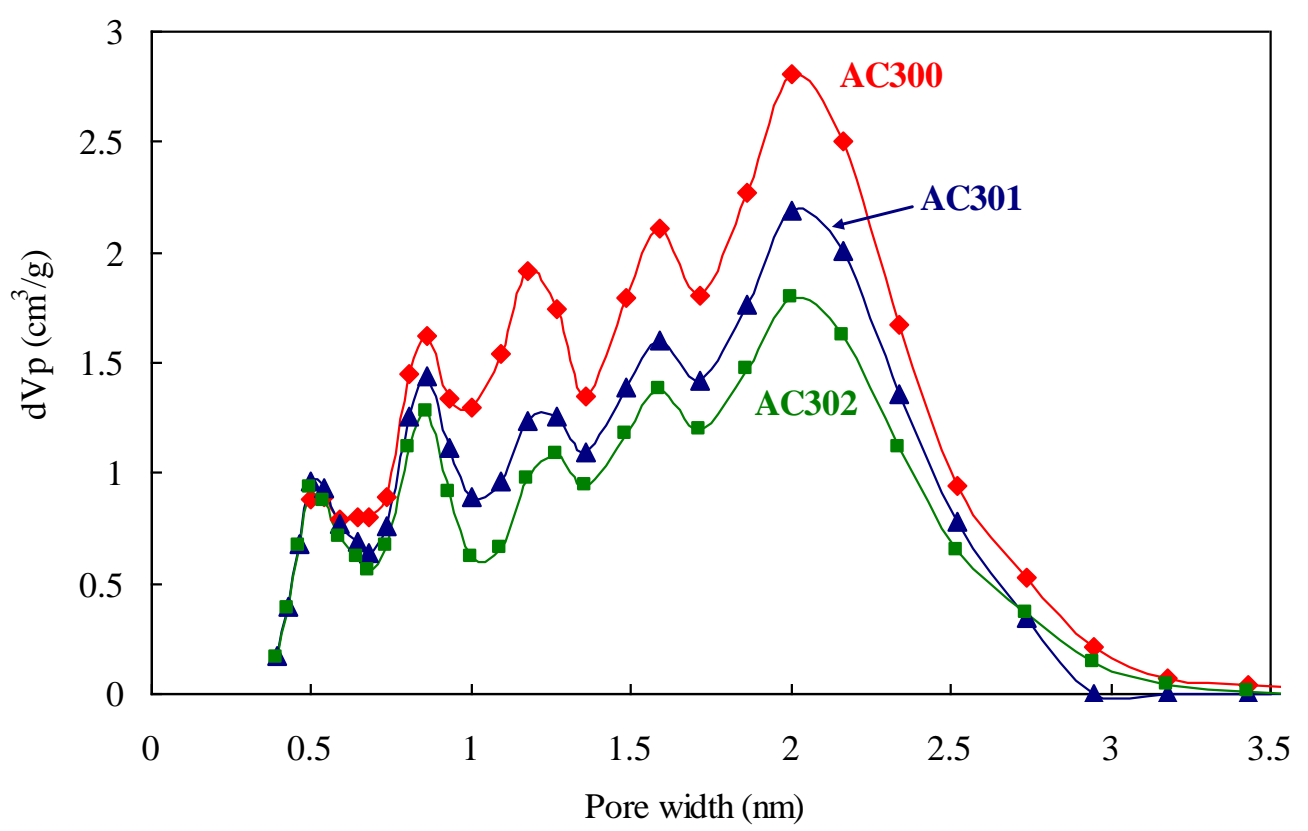


Figure 4

Hydrogen uptake of high surface area-activated carbons doped with nitrogen W. Zhao et al.

$\underline{\text { Figure } 4}$

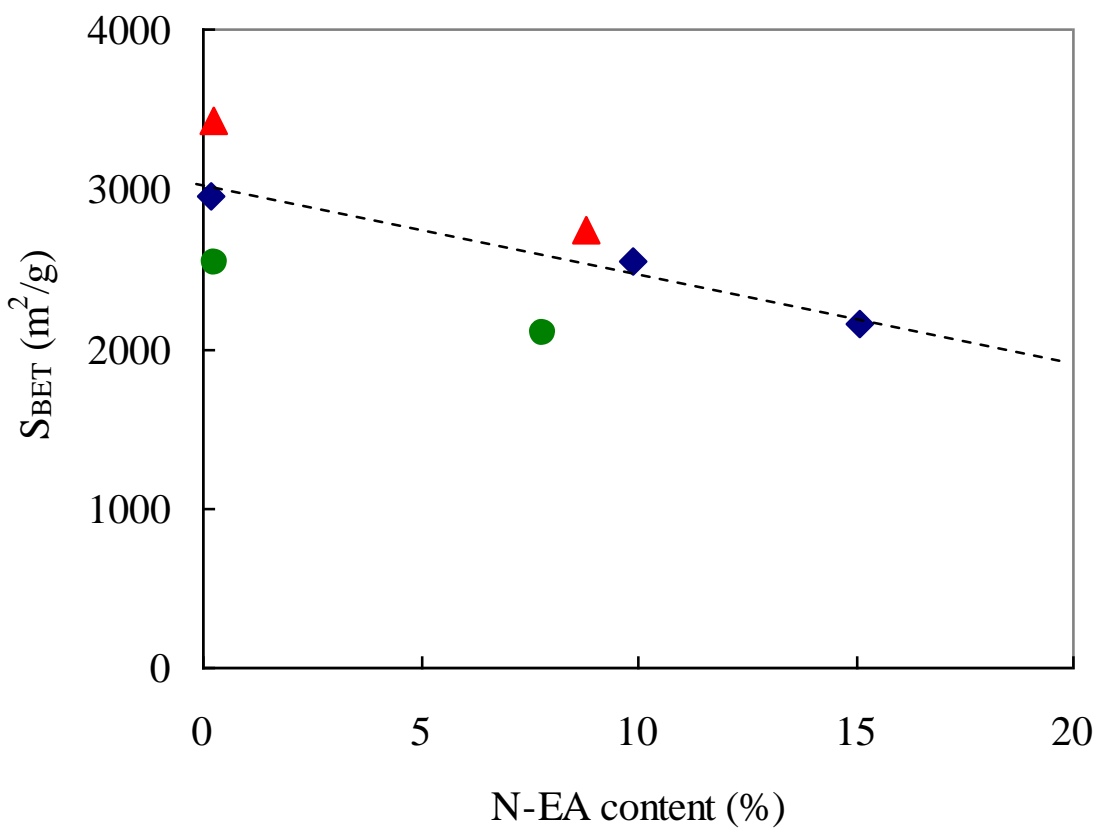


Hydrogen uptake of high surface area-activated carbons doped with nitrogen

W. Zhao et al.

Figure 5

a)

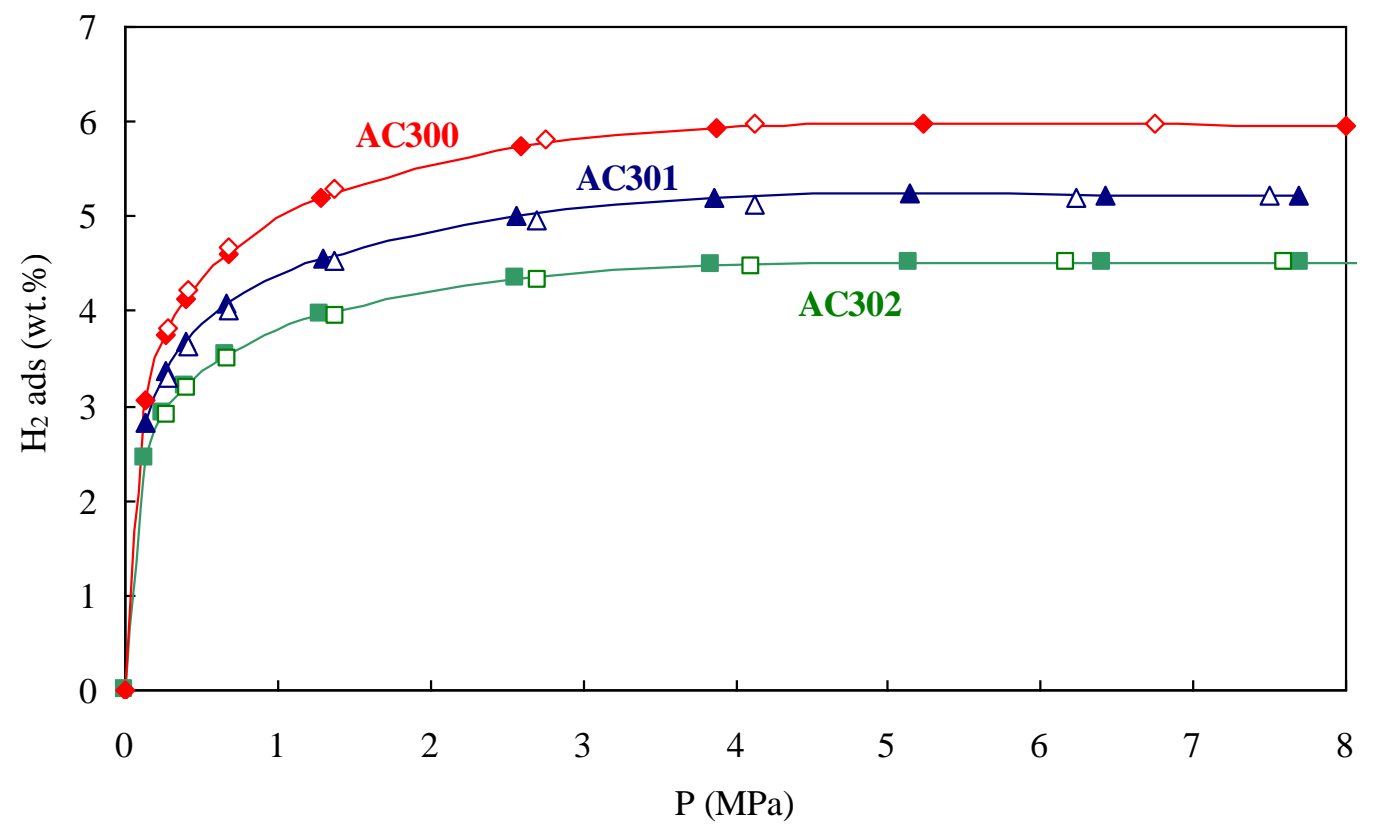

b)

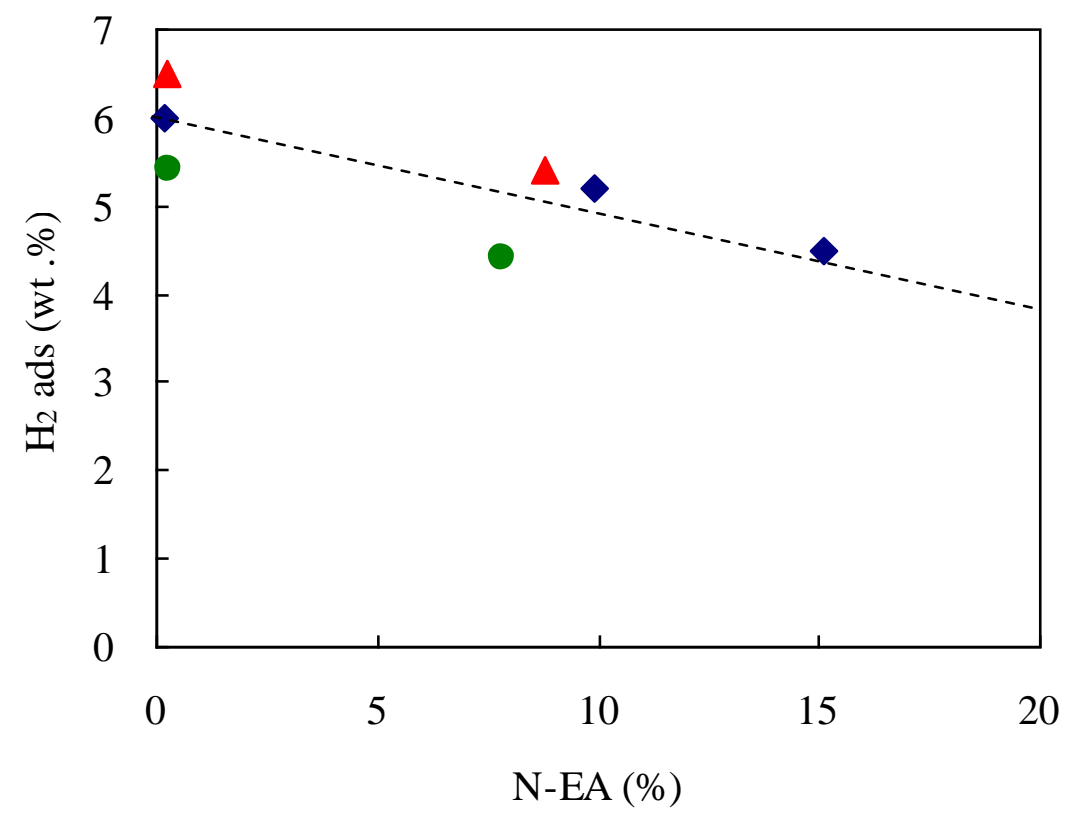


Hydrogen uptake of high surface area-activated carbons doped with nitrogen W. Zhao et al.

Figure 6

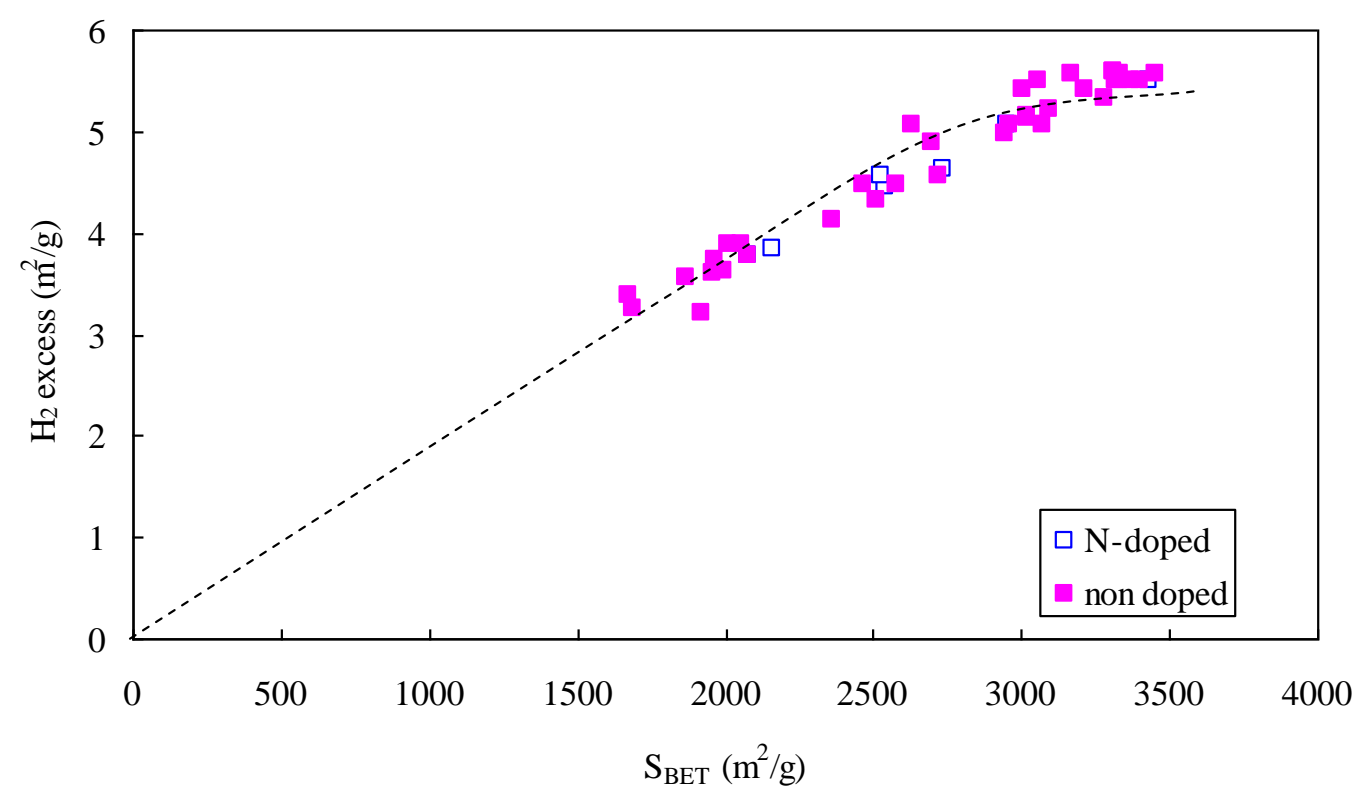


Hydrogen uptake of high surface area-activated carbons doped with nitrogen

W. Zhao et al.

\section{Figure 7}

a)



b)

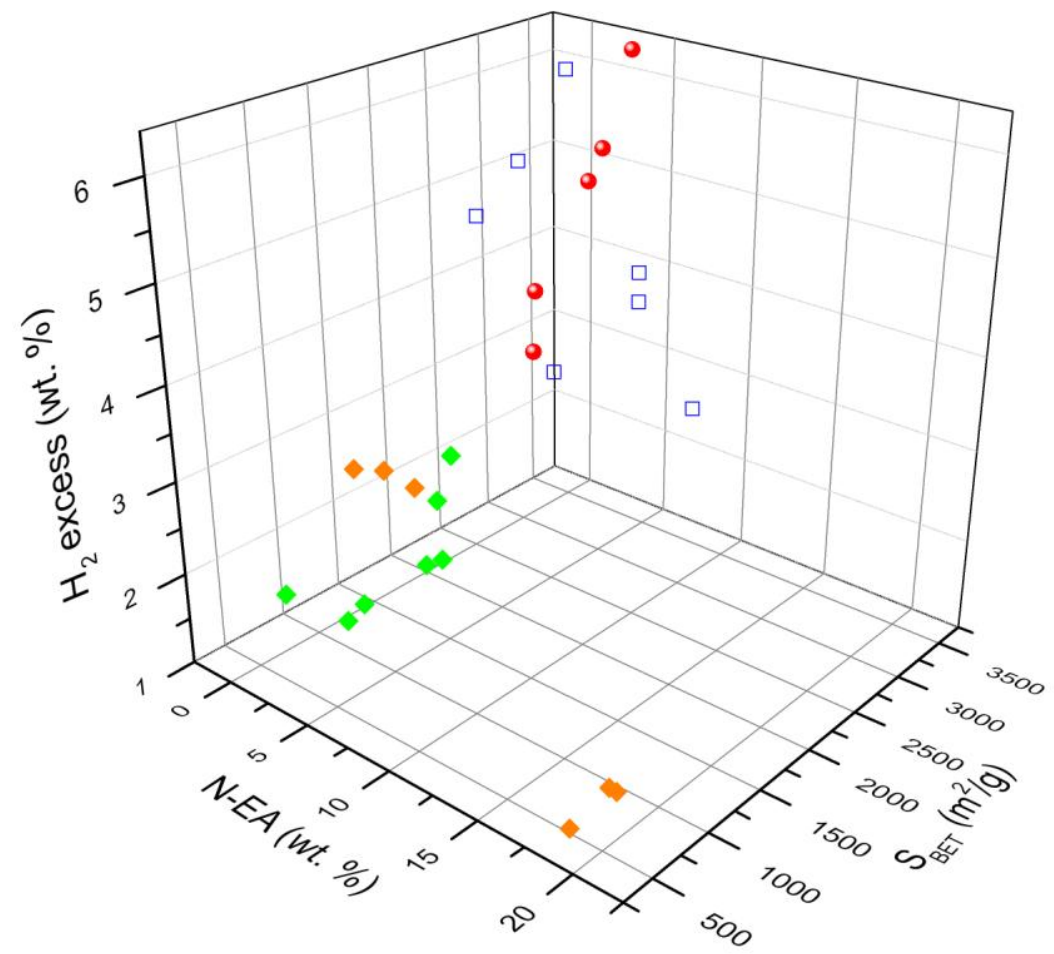


Hydrogen uptake of high surface area-activated carbons doped with nitrogen W. Zhao et al.

Figure 8




Supplementary Material

Click here to download Supplementary Material: vfierro_manuscript_revised_marked.doc 